\title{
Influence of Covalent Element $B$ and Si Addition on Magnetocaloric Properties of Gd-Co-Fe-(B,Si) Amorphous Alloys
}

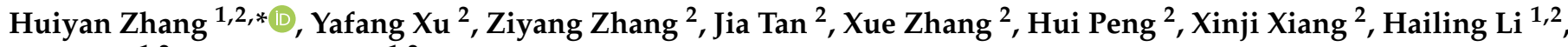 \\ Ailin $\mathrm{Xia}^{1,2}$ and Weihuo $\mathrm{Li}^{1,2}$ \\ 1 Key Laboratory of Green Fabrication and Surface Technology of Advanced Metal Materials, \\ Anhui University of Technology, Ma'anshan 243002, China; lhl_nano@163.com (H.L.); \\ alxia@126.com (A.X.); whli@ahut.edu.cn (W.L.) \\ 2 School of Materials Science and Engineering, Anhui University of Technology, Ma'anshan 243002, China; \\ xuyafang1212@outlook.com (Y.X.); zhangzy950429@163.com (Z.Z.); tanjia20212021@outlook.com (J.T.); \\ zxzyyxzhang@163.com (X.Z.); ph15256523687@163.com (H.P.); 15155685407@163.com (X.X.) \\ * Correspondence: hyzh2017@ahut.edu.cn; Tel.: +86-555-2311570
}

check for

updates

Citation: Zhang, H.; Xu, Y.; Zhang,

Z.; Tan, J.; Zhang, X.; Peng, H.; Xiang, X.; Li, H.; Xia, A.; Li, W. Influence of Covalent Element B and Si Addition on Magnetocaloric Properties of Gd-Co-Fe-(B,Si) Amorphous Alloys. Metals 2022, 12, 386. https:/ / doi.org/ $10.3390 /$ met12030386

Academic Editor: Volodymyr

A. Chernenko

Received: 5 January 2022

Accepted: 21 February 2022

Published: 23 February 2022

Publisher's Note: MDPI stays neutral with regard to jurisdictional claims in published maps and institutional affiliations.

Copyright: (c) 2022 by the authors. Licensee MDPI, Basel, Switzerland. This article is an open access article distributed under the terms and conditions of the Creative Commons Attribution (CC BY) license (https:// creativecommons.org/licenses/by/ $4.0 /)$.

\begin{abstract}
The effect of covalent element addition on the magnetic and magnetocaloric properties of ferrimagnetic $\mathrm{Gd}_{60} \mathrm{Co}_{20} \mathrm{Fe}_{20}$ amorphous alloy was studied. Particularly, the co-doping of $\mathrm{B}$ and Si promoted the magnetocaloric performance (with a larger magnetic entropy change $\left|\Delta S_{M}\right|$ at higher working temperature) of the initial $\mathrm{Gd}_{60} \mathrm{Co}_{20} \mathrm{Fe}_{20}$ amorphous alloy. This is possibly ascribed to the modified magnetic transition behavior. Additionally, the broadened magnetocaloric effect with $\left|\Delta S_{M}\right|$ of $2.25 \mathrm{~J} \mathrm{~kg}^{-1} \mathrm{~K}^{-1}$ at $222.5 \mathrm{~K}$ under a magnetic field change of 0-2 $\mathrm{T}$ and high relative cooling power of $396.0 \mathrm{~J} \mathrm{~kg}^{-1}$ were obtained for $\left(\mathrm{Gd}_{0.6} \mathrm{Co}_{0.2} \mathrm{Fe}_{0.2}\right)_{95} \mathrm{~B}_{2} \mathrm{Si}_{3}$. These properties reveal that the material could be a good candidate as a magnetic refrigerant suitable for active magnetic refrigerators.
\end{abstract}

Keywords: Gd-Co-Fe amorphous alloy; covalent element addition; magnetocaloric performance; magnetic refrigeration

\section{Introduction}

Compared with traditional gas compression refrigeration, magnetic refrigeration (MR) exhibits advantages of environmental friendliness, compactness, less noise, and higher efficiency and has attracted worldwide attention [1]. The working principle of MR is the intrinsic magnetocaloric effect (MCE) of magnetic materials, meaning when an external magnetic field is applied isothermally, the magnetic moment is parallelly aligned and the magnetic entropy decreases. Under the adiabatic condition, the total entropy of the magnetic materials remains unchanged, so the lattice and electron entropy increase to balance the variation in magnetic entropy, and then the system temperature becomes higher. The reverse process occurs when the magnetic field is removed. Therefore, the isothermal magnetic entropy change $\left|\Delta S_{M}\right|$ and the adiabatic temperature change $\Delta T_{\mathrm{ad}}$ are important parameters used to characterize the MCE [2].

Most of the near-room-temperature magnetic refrigerants are ferromagnetic, and the $\mathrm{MCE}$ reaches its maximum close to the Curie temperature $\left(T_{C}\right)$ [3]. Based on the order of magnetic transition, magnetocaloric materials can be classified into two types, namely first-order magnetic transition (FOMT) materials and second-order magnetic transition (SOMT) materials. FOMT materials undergo a discontinuous change in magnetization with varying temperature, so generally, they show a large $\left|\Delta S_{M}\right|$, e.g., $\mathrm{Gd}_{5} \mathrm{Si}_{2} \mathrm{Ge}_{2}$ [4], Mn-Fe-P-Si alloy [5], Ni-Mn-Si-based alloy [6], and $\mathrm{LaFe}_{11.83} \mathrm{Mn}_{0.32} \mathrm{Si}_{1.30} \mathrm{H}_{x}$ [7]. However, their drawbacks are the sharp drop in $\left|\Delta S_{M}\right|$ when the temperature deviates from $T_{\mathrm{C}}$, and the existence of magnetic and thermal hysteresis, which would reduce the refrigeration efficiency. In the case of SOMT materials, the magnetization changes with temperature continuously. Although their $\left|\Delta S_{M}\right|$ is lower than that of FOMT materials, they possess many 
merits, such as low thermal and magnetic hysteresis and a wider working temperature range, ensuring good magnetocaloric performance. The representative material is pure metal Gd, known as "prototype refrigerant" [3].

In general, magnetic amorphous alloys belong to SOMT materials. Except for the above-mentioned advantages, the unique atomic structure (long-range disordered and short-range ordered) provides amorphous alloys with properties of compositional tailoring, low eddy current losses, high corrosion resistance, etc. [8]. In the past 2 decades, Gdand Fe-based amorphous alloys have attracted more attention as candidates for nearroom-temperature magnetic refrigeration [1]. Among Gd-based amorphous alloys, the ferrimagnetic Gd-Co-Fe alloy system shows higher magnetocaloric performance than many Fe-based samples near room temperature [9]. Under an applied field changing from 0 to $2 \mathrm{~T}$, the peak value of the magnetic entropy change $\left(\left|\Delta S_{M}{ }^{p k}\right|\right)$ of $\mathrm{Gd}_{48} \mathrm{Co}_{50} \mathrm{Fe}_{2}$ and $\mathrm{Gd}_{50} \mathrm{Co}_{45} \mathrm{Fe}_{5}$ amorphous alloys is 1.98 and $1.85 \mathrm{~J} \mathrm{~kg}^{-1} \mathrm{~K}^{-1}$ at temperatures of 297 and $289 \mathrm{~K}$, respectively $[10,11]$.

However, the magnetic and magnetocaloric properties of Gd-Co-Fe amorphous alloys are sensitive to the Fe content: (1) When the element Co is substituted by a small amount of $\mathrm{Fe}, T_{C}$ increases to be closer to room temperature and $\left|\Delta S_{M}\right|$ decreases moderately [11,12]; (2) further replacement of $\mathrm{Co}$ with $\mathrm{Fe}$ (e.g., $\mathrm{Gd}_{60} \mathrm{Co}_{20} \mathrm{Fe}_{20}$ ) may cause the change in the magnetic exchange constant of antiferromagnetic $\mathrm{Gd}-\mathrm{Fe}$ interaction $\left(J_{\mathrm{Gd}-\mathrm{Fe}}\right)$ and then the deviation of the working temperature from $T_{C}$, which means the magnetic entropy change and working temperature drop simultaneously [13-15]. It has been reported that the magnetic transition behavior can be modified by adding covalent element B to GdFe amorphous alloys, owing to the increase in $J_{\mathrm{Gd}-\mathrm{Fe}}$ and decrease in the Fe magnetic moment [16]. In this study, the influence of adding covalent elements B and Si on the magnetic and magnetocaloric properties of $\mathrm{Gd}_{60} \mathrm{Co}_{20} \mathrm{Fe}_{20}$ amorphous alloy was studied, with the expectation to improve its magnetocaloric performance by modifying the internal magnetic properties.

\section{Materials and Methods}

The raw materials used to prepare the master alloys with nominal compositions of $\mathrm{Gd}_{60} \mathrm{Co}_{20} \mathrm{Fe}_{20}$ and $\left(\mathrm{Gd}_{0.6} \mathrm{Co}_{0.2} \mathrm{Fe}_{0.2}\right)_{95} \mathrm{~B}_{x} \mathrm{Si}_{5-x}(x=0,2,5)$ were pure metals $\mathrm{Gd}(99.9 \mathrm{wt} \%)$, Co $(99.9 w \mathrm{t} \%)$, and Fe (99.9 wt\%) and the prealloys of BFe and SiFe (the mass ratios of $\mathrm{B}$ to $\mathrm{Fe}$ and $\mathrm{Si}$ to Fe in BFe and SiFe were 17.62:81.46 and 22.25:74.53, respectively). The master alloys were produced using a vacuum arc-melting furnace under the protection of a high-purity argon atmosphere, and the ingots were remelted four times to ensure their compositional homogeneity. The small pieces of the ingots were put into quartz tubes and remelted through high-frequency induction in a high-purity argon atmosphere, and then ribbons with a width of $1.5-2 \mathrm{~mm}$ and a thickness of $25-30 \mu \mathrm{m}$ were manufactured by the single roller melt-spinning method at a wheel surface speed of $50 \mathrm{~m} / \mathrm{s}$.

Phase structure characterization of the as-spun ribbons was carried out by X-ray diffraction (XRD; D8 Advance, Bruker, Karlsruhe, Germany) using Cu K $\alpha$ radiation $(\lambda=0.15418 \mathrm{~nm})$ and a $2 \theta$ range of $20^{\circ}-80^{\circ}$. Thermal properties were measured by differential scanning calorimetry (DSC; STA 449F3, NETZSCH, Selb, Germany) at a heating rate of $0.33 \mathrm{~K} / \mathrm{s}$ with high-purity argon gas purged. In-plane magnetic hysteresis loops at different temperatures were detected by a magnetic property measurement system (MPMS; MPMS 3 , Quantum Design, San Diego, CA, USA). To investigate the magnetic transition behavior of the samples, the temperature dependence of the magnetization $(M-T)$ curve was recorded during the heating process from $100 \mathrm{~K}$ to $380 \mathrm{~K}$ under a magnetic field of $0.001 \mathrm{~T}$ after zero-field cooling (ZFC). The magnetocaloric performance of the ribbons was determined by the temperature dependence of the magnetic entropy change $\left|\Delta S_{M}\right|$ obtained through indirect measurement using the physical property measurement system (PPMS; PPMS-9T, Quantum Design, San Diego, CA, USA). The magnetization isotherms ( $M-H$ curves) at selected temperatures were observed under the applied magnetic field changing from 0 to 
$2 \mathrm{~T}$. Subsequently, according to the $M-H$ curves, the $\left|\Delta S_{M}\right|$ was calculated by the Maxwell relation [17]:

$$
\Delta S_{M}(T, H)=S_{M}(T, H)-S_{M}(T, 0)=\int_{0}^{H}\left\{\frac{\partial M(T, H)}{\partial T}\right\}_{H} \mathrm{~d} H
$$

Usually, the numerical approximation of the integral of the $M-H$ curves with small, discrete temperature intervals was used as the following equation [18]:

$$
\Delta S_{M}\left(\frac{T_{i+1}+T_{i}}{2}\right)=\sum_{i} \frac{M_{i+1}-M_{i}}{T_{i+1}-T_{i}} \Delta H_{i}
$$

where $M_{i}$ and $M_{i+1}$ are experimental values of magnetization at temperatures $T_{i}$ and $T_{i+1}$ under an applied magnetic field $H_{i}$, respectively. All the measurements of magnetic properties were performed with the magnetic field transverse to the alloy ribbons.

\section{Results and Discussion}

\subsection{Structural and Thermal Characterization}

Figure $1 \mathrm{a}$ exhibits the XRD patterns of the $\mathrm{Gd}_{60} \mathrm{Co}_{20} \mathrm{Fe}_{20}$ and $\left(\mathrm{Gd}_{0.6} \mathrm{Co}_{0.2} \mathrm{Fe}_{0.2}\right)_{95} \mathrm{~B}_{x} \mathrm{Si}_{5-x}$ $(x=0,2,5)$ as-spun ribbons. The typical broadened diffuse peaks indicate the amorphous structure of the samples. However, a few minor sharp peaks can be found. The ones marked with triangles and circles are possibly associated with $\mathrm{Gd}_{4} \mathrm{Co}_{3}$ and $\mathrm{Gd}_{12} \mathrm{Co}_{7}$ phases, respectively [19]. The precipitation of different crystalline phase resulted in the compositional variation of the amorphous matrix and a slight shift of the diffuse peak for different alloys.
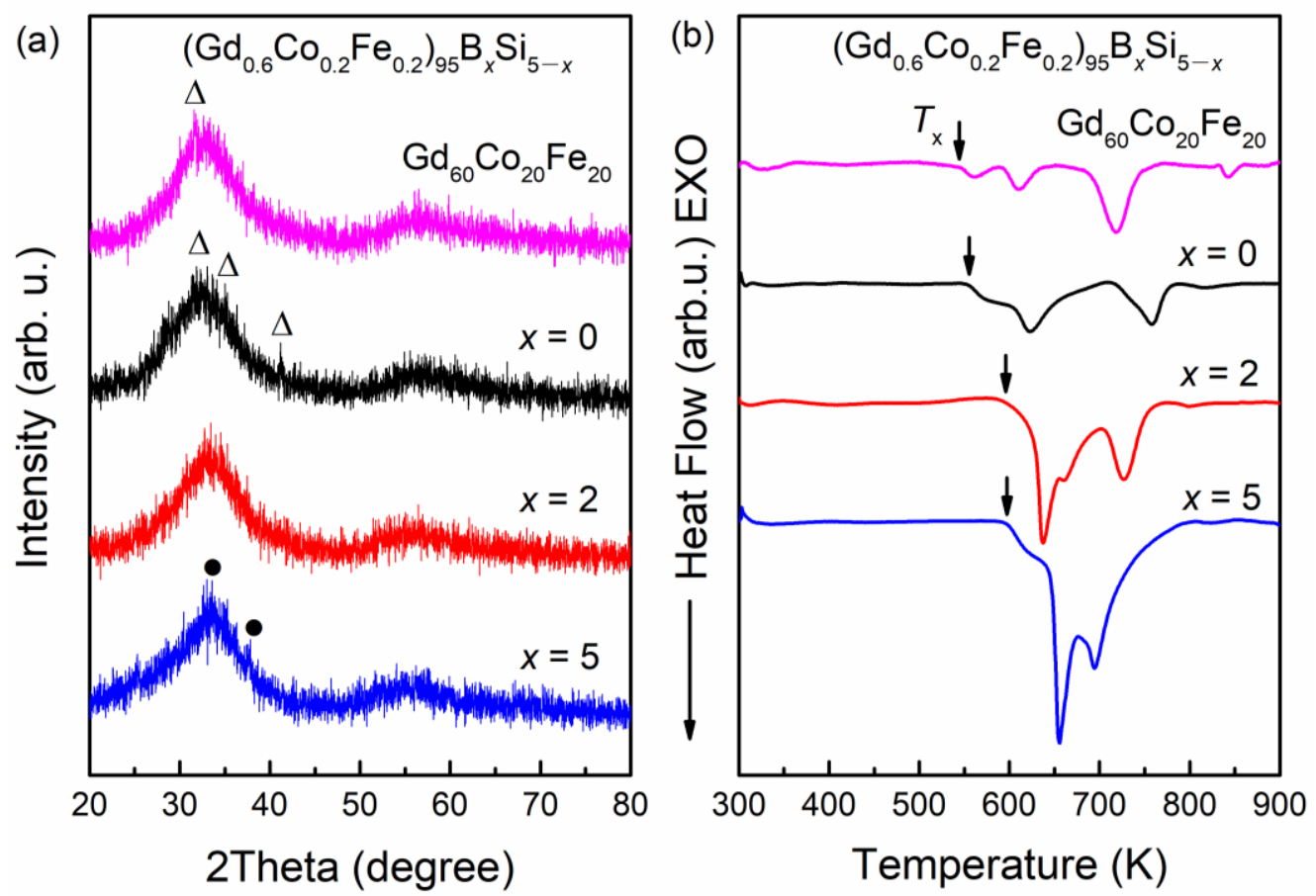

Figure 1. (a) XRD patterns and (b) DSC curves of the $\mathrm{Gd}_{60} \mathrm{Co}_{20} \mathrm{Fe}_{20}$ and $\left(\mathrm{Gd}_{0.6} \mathrm{Co}_{0.2} \mathrm{Fe}_{0.2}\right)_{95} \mathrm{~B}_{x} \mathrm{Si}_{5-x}$ $(x=0,2,5)$ as-spun ribbons.

The exothermic peak (corresponding to crystallization) on the DSC curves shown in Figure $1 \mathrm{~b}$ confirms the amorphous structure of the as-spun ribbons. The initial crystallization temperature $\left(T_{\mathrm{x}}\right)$ was determined by the intersection of the extrapolated base line and the steepest tangent to the first exothermic peak. In this research, $T_{x}$ of $\left(\mathrm{Gd}_{0.6} \mathrm{Co}_{0.2} \mathrm{Fe}_{0.2}\right)_{95} \mathrm{Si}_{5}$, $\left(\mathrm{Gd}_{0.6} \mathrm{Co}_{0.2} \mathrm{Fe}_{0.2}\right)_{95} \mathrm{~B}_{2} \mathrm{Si}_{3}$, and $\left(\mathrm{Gd}_{0.6} \mathrm{Co}_{0.2} \mathrm{Fe}_{0.2}\right)_{95} \mathrm{~B}_{5}$ was 555 , 596, and $597 \mathrm{~K}$, respectively, 
higher than that of $\mathrm{Gd}_{60} \mathrm{Co}_{20} \mathrm{Fe}_{20}(544 \mathrm{~K})$. Therefore, the addition of covalent element $\mathrm{B}$ or $\mathrm{Si}$ enhances the thermal stability of $\left(\mathrm{Gd}_{0.6} \mathrm{Co}_{0.2} \mathrm{Fe}_{0.2}\right){ }_{95} \mathrm{~B}_{x} \mathrm{Si}_{5-x}$ amorphous alloys, and $\left(\mathrm{Gd}_{0.6} \mathrm{Co}_{0.2} \mathrm{Fe}_{0.2}\right)_{95} \mathrm{~B}_{2} \mathrm{Si}_{3}$ possesses the best thermal stability [20]. In addition, the $T_{\mathrm{x}}$ of each sample was high enough to maintain its amorphous structure at room temperature. At higher temperature, more exothermic peaks were obtained, which is ascribed to the formation of different phases at different stages of heating [21]. With increasing B content, the exotherms became sharper and moved closer to each other.

\subsection{Magnetic Properties}

Figure 2a displays the ZFC M-T curves of the $\mathrm{Gd}_{60} \mathrm{Co}_{20} \mathrm{Fe}_{20}$ and $\left(\mathrm{Gd}_{0.6} \mathrm{Co}_{0.2} \mathrm{Fe}_{0.2}\right)_{95} \mathrm{~B}_{x} \mathrm{Si}_{5-x}$ $(x=0,2,5)$ amorphous alloys under a magnetic field of $0.001 \mathrm{~T}$, respectively. With increasing temperature, the magnetic transition from ferrimagnetic to paramagnetic could be observed in all the alloys near the Curie temperature $\left(T_{C}\right)$. In this study, we used the inflection point method to determine $T_{C}$, i.e., the temperature corresponding to the minimum of the $\mathrm{d} M / \mathrm{d} T-T$ curves, as illustrated in Figure $2 \mathrm{~b}$. For $x=0,2$, and 5, the values of $T_{\mathrm{C}}$ were 256, 230 , and $212 \mathrm{~K}$, lower than that of $\mathrm{Gd}_{60} \mathrm{Co}_{20} \mathrm{Fe}_{20}\left(T_{\mathrm{C}}=338 \mathrm{~K}\right)$. Moreover, $\mathrm{Gd}_{60} \mathrm{Co}_{20} \mathrm{Fe}_{20}$ showed a broad magnetic transition with respect to temperature, which became narrower after adding B and Si. The magnetic transition behavior is closely related to the internal magnetic exchange interaction $[11,15,22,23]$, and the phenomenon can be interpreted as follows: The introduction of $\mathrm{B}$ weakens the magnetic moment of Fe and enhances the antiferromagnetic exchange interaction between $\mathrm{Gd}$ and $\mathrm{Fe}$, and then results in a reduction in $T_{C}$ and a sharpened magnetic transition process [16]. The covalent element $\mathrm{Si}$ may have an analogous effect.

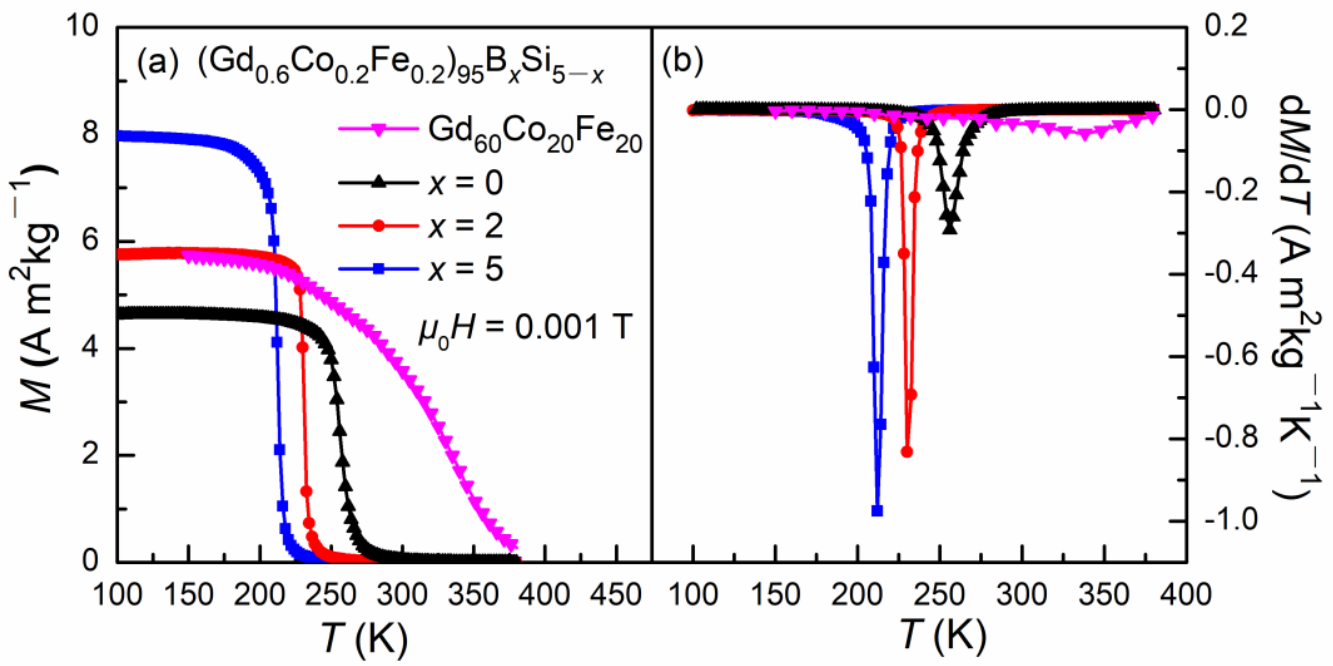

Figure 2. $M-T$ curves of the $\mathrm{Gd}_{60} \mathrm{Co}_{20} \mathrm{Fe}_{20}$ and $\left(\mathrm{Gd}_{0.6} \mathrm{Co}_{0.2} \mathrm{Fe}_{0.2}\right)_{95} \mathrm{~B}_{x} \mathrm{Si}_{5-x}(x=0,2,5)$ amorphous alloys under an applied magnetic field of (a) $0.001 \mathrm{~T}$ and (b) the correlating curves of $\mathrm{d} M / \mathrm{d} T$ vs. $T$.

\subsection{Magnetocaloric Properties}

The isothermal magnetization $(M-H)$ curves of the $\mathrm{Gd}_{60} \mathrm{Co}_{20} \mathrm{Fe}_{20}$ and $\left(\mathrm{Gd}_{0.6} \mathrm{Co}_{0.2} \mathrm{Fe}_{0.2}\right)_{95} \mathrm{~B}_{x} \mathrm{Si}_{5-x}$ amorphous alloys at different selected temperatures under an applied magnetic field change of $0-2 \mathrm{~T}$ are shown in Figure $3 \mathrm{a}-\mathrm{d}$. In this study, a temperature interval of $15 \mathrm{~K}$ and $2 \mathrm{~K}$ (or $5 \mathrm{~K}$ ) was chosen for the temperature region far away from and in the vicinity of $T_{C}$, respectively. It can be seen that with increasing temperature, the magnetization decreased and the magnetic state gradually changed from ferrimagnetism to paramagnetism. $\Delta S_{M}$ can be calculated from the data of the $M-H$ curves on basis of the Equation (2), and the temperature dependence of $\left|\Delta S_{M}\right|$ is shown in Figure 4 . Under the magnetic field changing from 0 to $2 \mathrm{~T}$, the $\left|\Delta S_{M}{ }^{p k}\right|$ of $\left(\mathrm{Gd}_{0.6} \mathrm{Co}_{0.2} \mathrm{Fe}_{0.2}\right)_{95} \mathrm{Si}_{5}$, $\left(\mathrm{Gd}_{0.6} \mathrm{Co}_{0.2} \mathrm{Fe}_{0.2}\right)_{95} \mathrm{~B}_{2} \mathrm{Si}_{3}$, and $\left(\mathrm{Gd}_{0.6} \mathrm{Co}_{0.2} \mathrm{Fe}_{0.2}\right)_{95} \mathrm{~B}_{5}$ amorphous alloys was 1.92, 2.25, and $2.27 \mathrm{~J} \mathrm{~kg}^{-1} \mathrm{~K}^{-1}$, respectively, higher than that of $\mathrm{Gd}_{60} \mathrm{Co}_{20} \mathrm{Fe}_{20}\left(1.71 \mathrm{~J} \mathrm{~kg}^{-1} \mathrm{~K}^{-1}\right)$. The tem- 
perature corresponding to $\left|\Delta S_{M}{ }^{p k}\right|$ under $2 \mathrm{~T}$ was denoted as $T_{p k}$, and the values of $T_{\mathrm{pk}}$ for $x=0,2$, and 5 and $\mathrm{Gd}_{60} \mathrm{Co}_{20} \mathrm{Fe}_{20}$ were 205, 222.5, 202.5, and $205 \mathrm{~K}$, respectively. Therefore, the co-addition of $\mathrm{Si}$ and B not only improves $\left|\Delta S_{M}{ }^{p k}\right|$ but also raises the working temperature. The large inconsistency between $T_{p k}$ and $T_{C}$ is worth noting, which is possibly attributed to the local inhomogeneity in the amorphous matrix, such as nanocrystalline (observed in Figure 1a), clusters, or free volume [15,24].

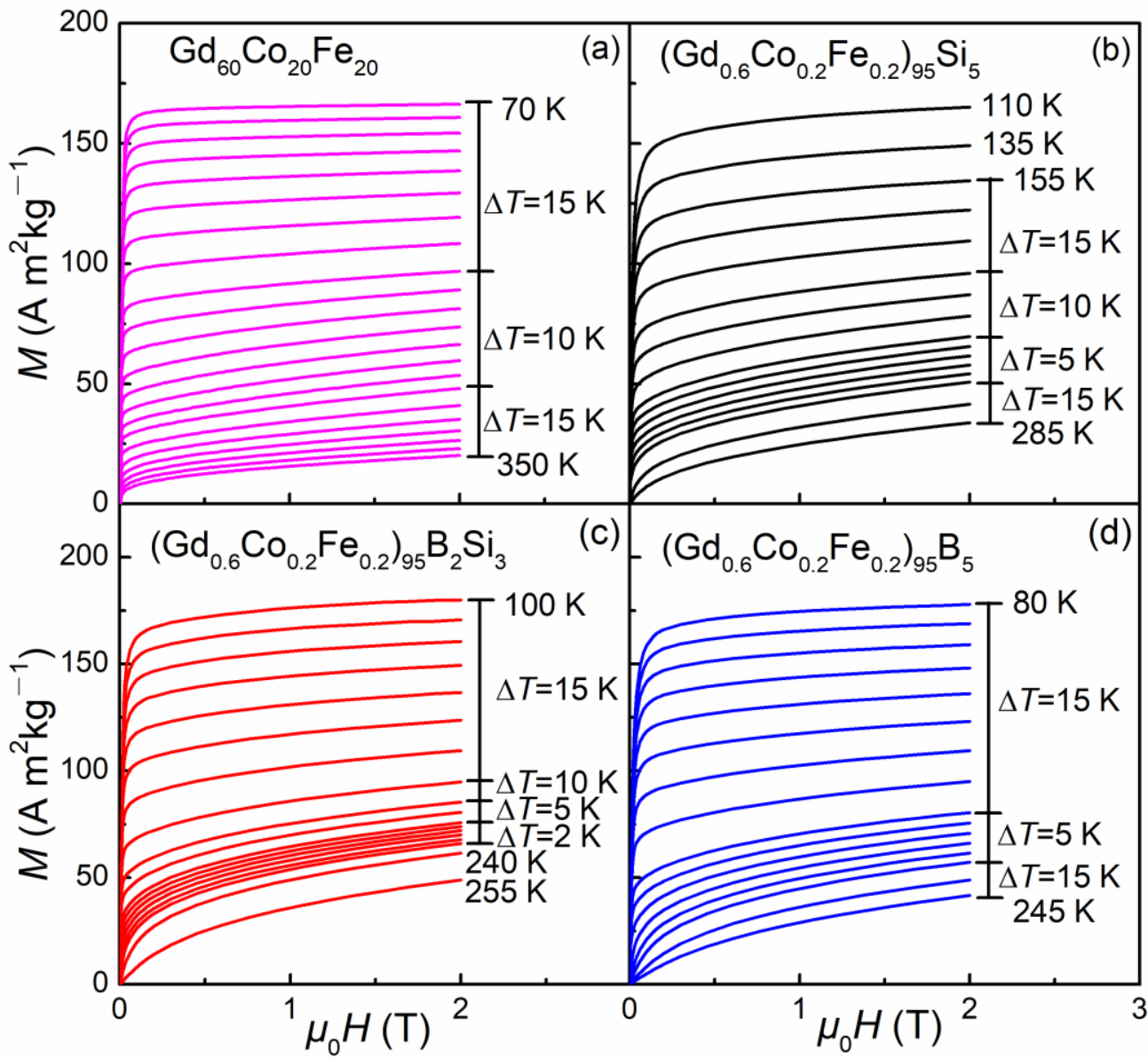

Figure 3. The $M-H$ curves of the (a) $\mathrm{Gd}_{60} \mathrm{Co}_{20} \mathrm{Fe}_{20}$ and $\left(\mathrm{Gd}_{0.6} \mathrm{Co}_{0.2} \mathrm{Fe}_{0.2}\right)_{95} \mathrm{~B}_{x} \mathrm{Si}_{5-x}$ amorphous ribbons with $x=(\mathbf{b}) 0$, (c) 2, and (d) 5 at selected temperatures.

As listed in Table 1, the $\mid \Delta S_{M}{ }^{p k}$ | of the $\left(\mathrm{Gd}_{0.6} \mathrm{Co}_{0.2} \mathrm{Fe}_{0.2}\right)_{95} \mathrm{~B}_{2} \mathrm{Si}_{3}$ amorphous ribbon was larger than that of $\mathrm{Gd}_{60} \mathrm{Co}_{30} \mathrm{Fe}_{10}, \mathrm{Gd}_{75}\left(\mathrm{Fe}_{0.75} \mathrm{Co}_{0.25}\right)_{25}$, and some Fe-based amorphous counterparts with similar $T_{p k}$ but lower than that of Gd-Co-based amorphous alloys with a small amount of $\mathrm{Fe}$ or without $\mathrm{Fe}$, such as $\mathrm{Gd}_{60} \mathrm{Co}_{35} \mathrm{Fe}_{5}$ and $\mathrm{Gd}_{56} \mathrm{Co}_{44}$. Another parameter used to evaluate the MCE is the relative cooling power (RCP), which represents the heat transfer between the hot and cold reservoirs in an ideal refrigeration cycle, and can be described as:

$$
R C P=\left|\Delta S_{M}^{p k}\right| \times \Delta T_{F W H M},
$$

where $\Delta T_{F W H M}$ is defined as the full width at half maximum of the $\left|\Delta S_{M}\right|-T$ curve [1]. A large RCP of $396.0 \mathrm{~J} \mathrm{~kg}^{-1}$ was obtained in the $\left(\mathrm{Gd}_{0.6} \mathrm{Co}_{0.2} \mathrm{Fe}_{0.2}\right){ }_{95} \mathrm{~B}_{2} \mathrm{Si}_{3}$ sample, and the value of $\left|\Delta S_{M}\right|$ was nearly constant $\left(2.20 \pm 0.05 \mathrm{~J} \mathrm{~kg}^{-1} \mathrm{~K}^{-1}\right)$ among a wide temperature range of 198-233 K, i.e., the so-called table-like MCE, which makes it more suitable for Ericsson-cycle refrigeration [25]. It is probable that the exchange interaction of local magnetic clusters with different ordering temperature results in a broad magnetic transition, leading to the broadened $\left|\Delta S_{M}\right|-T$ curve and significant RCP enhancement [11]. In this study, the $\left(\mathrm{Gd}_{0.6} \mathrm{Co}_{0.2} \mathrm{Fe}_{0.2}\right)_{95} \mathrm{~B}_{2} \mathrm{Si}_{3}$ amorphous alloy exhibited superior performance compared to 
the partially crystallized $\mathrm{Gd}_{55} \mathrm{Ni}_{10} \mathrm{Co}_{35}\left(\left|\Delta S_{M}\right|\right.$ maintained the value of $\sim 2.03 \mathrm{~J} \mathrm{~kg}^{-1} \mathrm{~K}^{-1}$ within $179-205 \mathrm{~K})$ and dual-phase $\mathrm{Gd}_{48} \mathrm{CO}_{50} \mathrm{Nb}_{2}$ ribbons $\left(\left|\Delta S_{M}\right|\right.$ maintained its value of $\sim 1.7 \mathrm{~J} \mathrm{~kg}^{-1} \mathrm{~K}^{-1}$ within a temperature range of 220-265 K) [26,27].

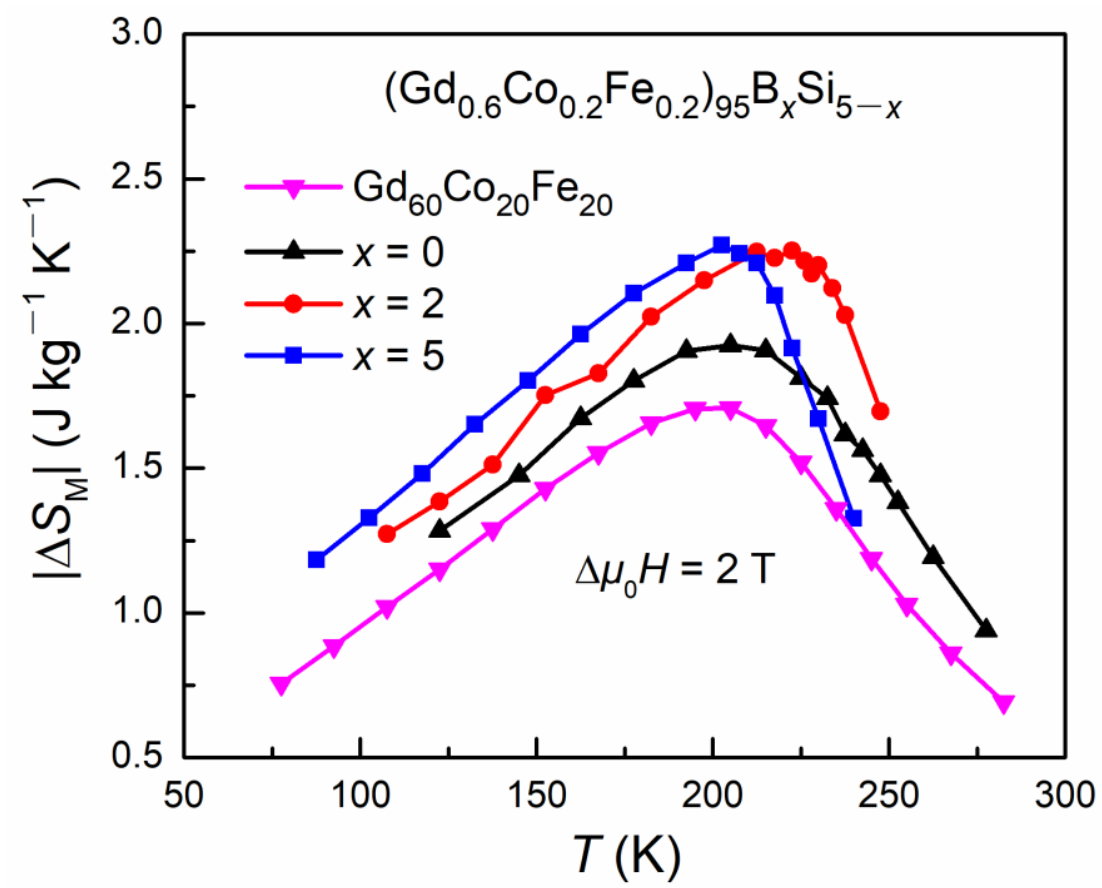

Figure 4. The correlation between magnetic entropy change and temperature of the $\mathrm{Gd}_{60} \mathrm{Co}_{20} \mathrm{Fe}_{20}$ and $\left(\mathrm{Gd}_{0.6} \mathrm{Co}_{0.2} \mathrm{Fe}_{0.2}\right)_{95} \mathrm{~B}_{x} \mathrm{Si}_{5-x}$ amorphous alloys.

Table 1. Magnetic and magnetocaloric properties of various materials with a similar working temperature range ( $\mathrm{A}$ and $\mathrm{C}$ indicate amorphous and crystalline structures, respectively.).

\begin{tabular}{|c|c|c|c|c|c|c|c|}
\hline \multirow{2}{*}{ Alloys } & \multirow{2}{*}{ Structure } & $\begin{array}{l}T_{\mathrm{C}} \\
(\mathrm{K})\end{array}$ & $\begin{array}{l}T_{p k} \\
(\mathrm{~K})\end{array}$ & $\begin{array}{c}\left|\Delta S_{M}^{p k}\right| \\
\left(\mathrm{J} \mathrm{kg}^{-1} \mathrm{~K}^{-1}\right)\end{array}$ & $\begin{array}{l}\Delta T_{F W H M} \\
\text { (K) }\end{array}$ & $\begin{array}{c}\mathrm{RCP} \\
\left(\mathrm{J} \mathrm{kg}^{-1}\right)\end{array}$ & \multirow{2}{*}{ Reference } \\
\hline & & $\mu_{0} H=0.001 \mathrm{~T}$ & \multicolumn{4}{|c|}{$\mu_{0} H=2 \mathrm{~T}$} & \\
\hline$\left(\mathrm{Gd}_{0.6} \mathrm{Co}_{0.2} \mathrm{Fe}_{0.2}\right)_{95} \mathrm{~B}_{5}$ & A & 212 & 202.5 & 2.27 & 162 & 367.7 & This work \\
\hline$\left(\mathrm{Gd}_{0.6} \mathrm{Co}_{0.2} \mathrm{Fe}_{0.2}\right)_{95} \mathrm{~B}_{2} \mathrm{Si}_{3}$ & A & 230 & 222.5 & 2.25 & 176 & 396.0 & This work \\
\hline$\left(\mathrm{Gd}_{0.6} \mathrm{Co}_{0.2} \mathrm{Fe}_{0.2}\right)_{95} \mathrm{Si}_{5}$ & A & 256 & 205 & 1.92 & 190 & 364.8 & This work \\
\hline $\mathrm{Gd}_{60} \mathrm{Co}_{20} \mathrm{Fe}_{20}$ & A & 338 & 205 & 1.71 & 178 & 304.4 & This work \\
\hline $\mathrm{Gd}_{48} \mathrm{Co}_{50} \mathrm{Nb}_{2}$ & A & $220 / 264$ & $\sim 220$ & 1.7 & 145 & $\sim 246.5$ & [26] \\
\hline $\begin{array}{c}\mathrm{Gd}_{55} \mathrm{Ni}_{10} \mathrm{Co}_{35} \\
(533 \mathrm{~K} \text { annealing) }\end{array}$ & $A+C$ & 212 & 212 & 2.03 & 148 & $\sim 300$ & [27] \\
\hline $\mathrm{Fe}_{89} \mathrm{Co}_{1} \mathrm{Sc}_{10}$ & A & 196 & 210 & 1.24 & 182 & 225.7 & [28] \\
\hline$\left(\mathrm{Fe}_{93} \mathrm{Zr}_{7}\right)_{89} \mathrm{H}_{11}$ & A & 200 & $\sim 215$ & 1.008 & 145.6 & 146.75 & [29] \\
\hline $\mathrm{Gd}_{75}\left(\mathrm{Fe}_{0.75} \mathrm{Co}_{0.25}\right)_{25}$ & $A+C$ & 223 & $\sim 220$ & 2.0 & - & - & [30] \\
\hline $\mathrm{Gd}_{60} \mathrm{Co}_{30} \mathrm{Fe}_{10}$ & A & 239 & 222.5 & 2.08 & 154 & $\sim 320$ & [31] \\
\hline $\mathrm{Gd}_{60} \mathrm{Co}_{35} \mathrm{Fe}_{5}$ & A & 222 & 222.5 & 2.91 & 104 & $\sim 303$ & [31] \\
\hline $\mathrm{Gd}_{56} \mathrm{Co}_{44}$ & A & 216 & $\sim 215$ & 3.34 & 85 & $\sim 284$ & [32] \\
\hline
\end{tabular}

To determine the magnetic transition behavior in the $\mathrm{Gd}_{60} \mathrm{Co}_{20} \mathrm{Fe}_{20}$ and $\left(\mathrm{Gd}_{0.6} \mathrm{Co}_{0.2} \mathrm{Fe}_{0.2}\right)_{95} \mathrm{~B}_{x} \mathrm{Si}_{5-x}$ amorphous alloys, Arrott plots $\left(M^{2}\right.$ vs. $\left.\mathrm{H} / \mathrm{M}\right)$ converted from the isotherms are illustrated in Figure 5. According to the Banerjee criterion, the second-order transition can be identified when the slope of all the plots is positive, while the negative slope corresponds to the first-order transition [33]. In this case, all the slopes of Arrott plots were positive, which demonstrates the magnetic phase transition is of the second order. Figure 6 shows the hysteresis loops detected at 10, 200, 300, and $400 \mathrm{~K}$ for $\mathrm{Gd}_{60} \mathrm{Co}_{20} \mathrm{Fe}_{20}$ and 
$\left(\mathrm{Gd}_{0.6} \mathrm{Co}_{0.2} \mathrm{Fe}_{0.2}\right)_{95} \mathrm{~B}_{x} \mathrm{Si}_{5-x}$ ribbons. The samples were almost soft magnetic with negligible hysteresis at 10 and $200 \mathrm{~K}$ and were paramagnetic at $400 \mathrm{~K}$.
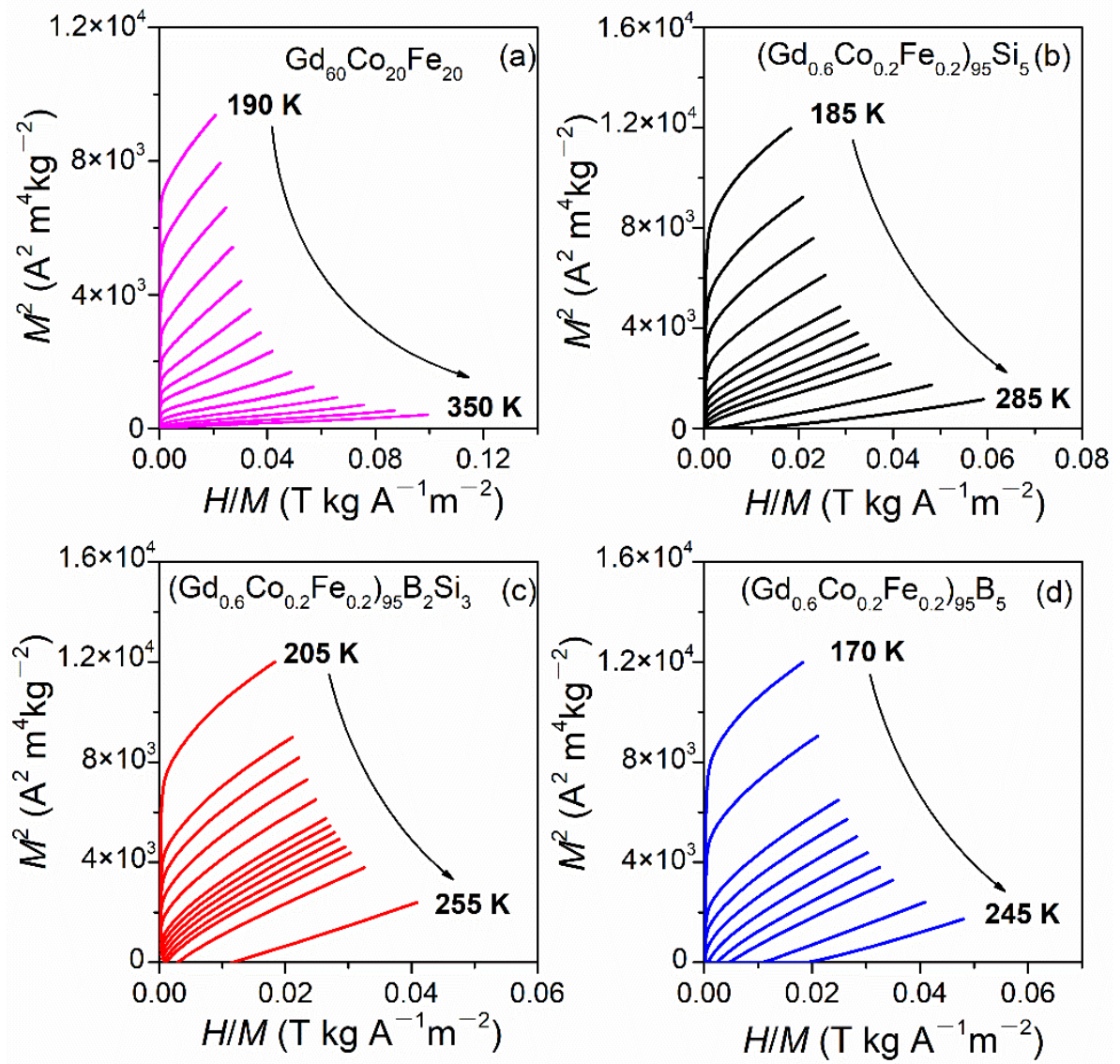

Figure 5. Arrott plots of amorphous alloys, (a) $\mathrm{Gd}_{60} \mathrm{Co}_{20} \mathrm{Fe}_{20}$ and $\left(\mathrm{Gd}_{0.6} \mathrm{Co}_{0.2} \mathrm{Fe}_{0.2}\right)_{95} \mathrm{~B}_{x} \mathrm{Si}_{5-x}$ with $x=(\mathbf{b}) 0$, (c) 2, and (d) 5, derived from the $M-H$ isotherms.

For the second-order magnetic phase transition, a universal relation of the field dependence of the magnetic entropy change was proposed by Oesterreicher and Parker, as the following equation [34]:

$$
\left|\Delta S_{M}\right| \propto H^{n}
$$

where $\mathrm{n}$ is an exponent correlated with both $H$ and $T$ and can be locally calculated as:

$$
n(H, T)=\frac{d \ln \left|\Delta S_{M}\right|}{d \ln H}
$$

In the particular case of $T=T_{\mathrm{C}}$ or $T_{p k}$, the $n$ exponent becomes field independent [35]. Figure 7 exhibits the fitting results of the $\ln \left|\Delta S_{M^{p k}}\right|$ vs. $\ln H$ plots, and the values of $n\left(T_{p k}\right)$ for the $\mathrm{Gd}_{60} \mathrm{Co}_{20} \mathrm{Fe}_{20}$ and $\left(\mathrm{Gd}_{0.6} \mathrm{Co}_{0.2} \mathrm{Fe}_{0.2}\right)_{95} \mathrm{~B}_{x} \mathrm{Si}_{5-x}(x=0,2,5)$ amorphous alloys were $0.93,0.95,0.87$, and 0.87 . It can be found all the $n$ exponents deviate from the value of $2 / 3$ corresponding to mean field theory and the value of $0.72 \pm 0.05$ predicted in some amorphous alloys [36-38] but are close to the values observed in some Fe-containing Gdbased metallic glasses, e.g., $\mathrm{Gd}_{50} \mathrm{Co}_{45} \mathrm{Fe}_{5}(n=0.837)$ [10] and $\mathrm{Gd}_{60} \mathrm{Fe}_{20} \mathrm{Al}_{20}(n=0.869)$ [14]. The deviation is probably ascribed to the local inhomogeneity of the structure, since the critical exponents for the mean-field model are highly sensitive to the microstructure of the amorphous alloys $[10,14,39]$. 

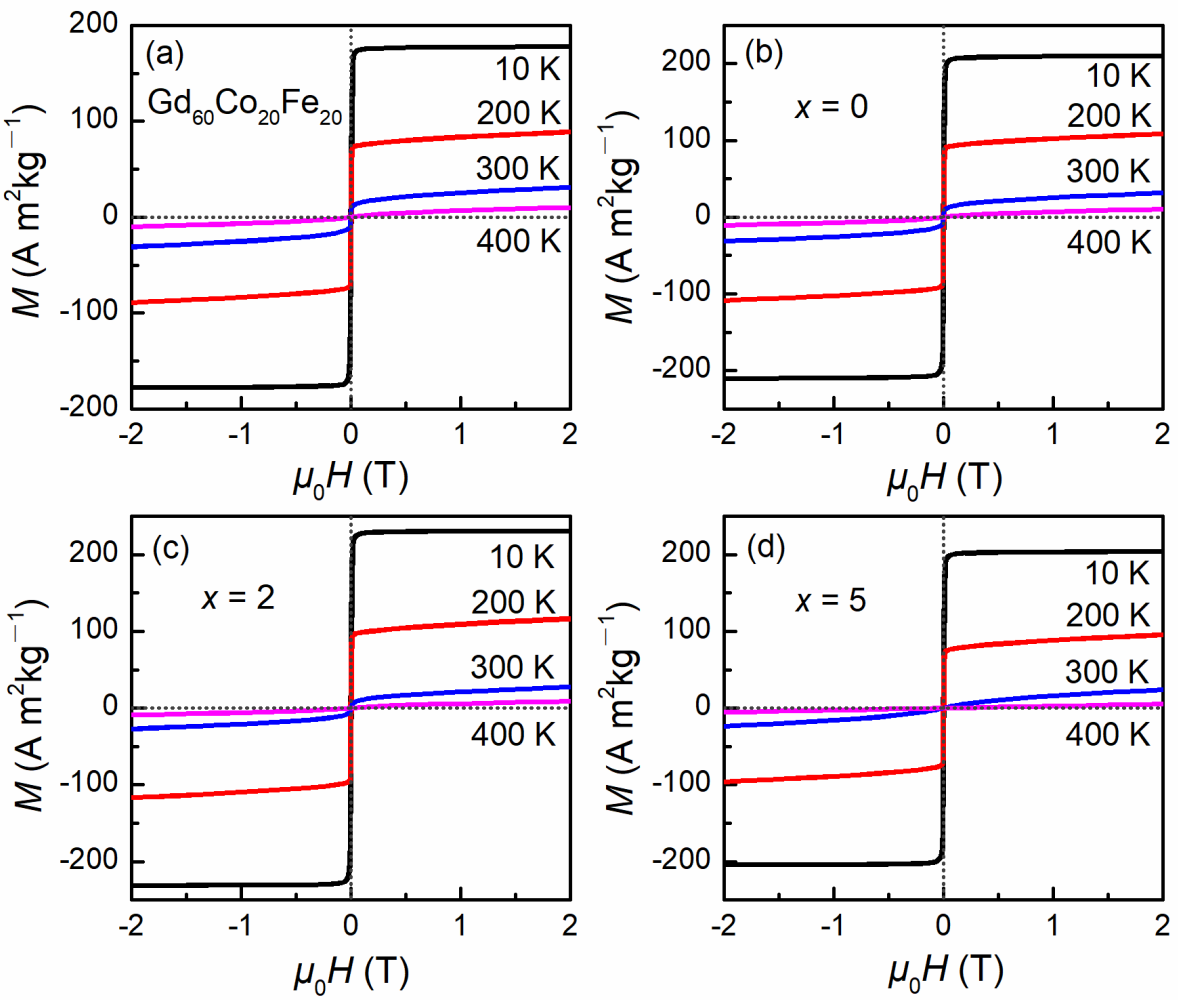

Figure 6. Magnetic hysteresis loops of (a) $\mathrm{Gd}_{60} \mathrm{Co}_{20} \mathrm{Fe}_{20}$ and (b-d) $\left(\mathrm{Gd}_{0.6} \mathrm{Co}_{0.2} \mathrm{Fe}_{0.2}\right)_{95} \mathrm{~B}_{x} \mathrm{Si}_{5-x}(x=0$, $2,5)$ amorphous alloys at different temperatures.

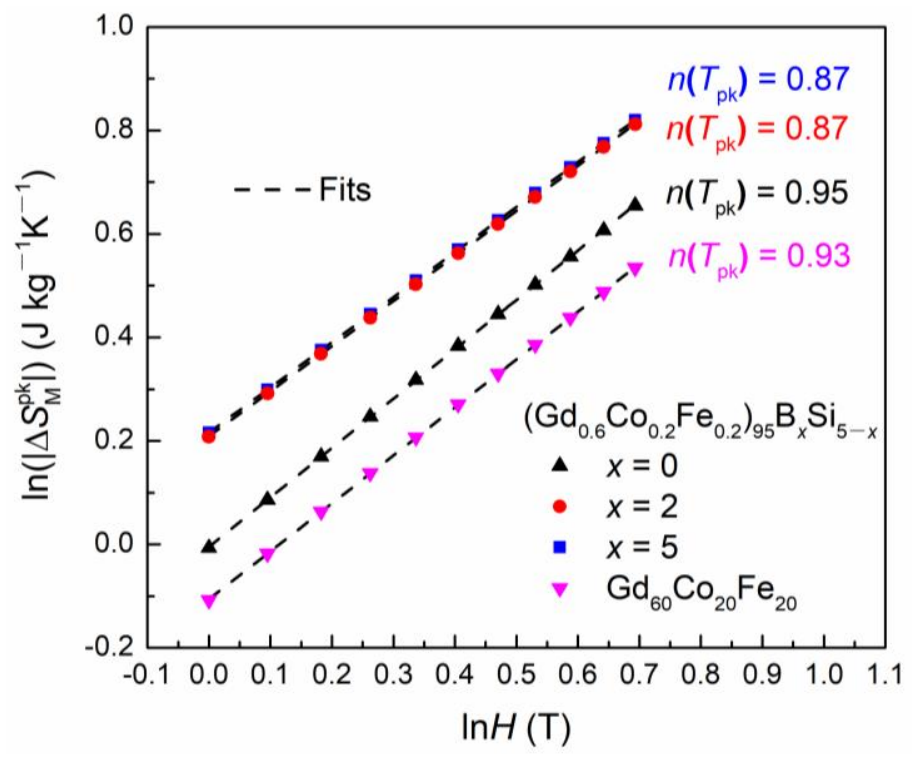

Figure 7. Ln-Ln plots of the field dependence of $\left|\Delta S_{M}{ }^{p k}\right|$ with the calculated $n\left(T_{p k}\right)$ exponent for the $\mathrm{Gd}_{60} \mathrm{Co}_{20} \mathrm{Fe}_{20}$ and $\left(\mathrm{Gd}_{0.6} \mathrm{Co}_{0.2} \mathrm{Fe}_{0.2}\right)_{95} \mathrm{~B}_{x} \mathrm{Si}_{5-x}$ amorphous ribbons.

\section{Conclusions}

To summarize, $\mathrm{Gd}_{60} \mathrm{Co}_{20} \mathrm{Fe}_{20}$ and $\left(\mathrm{Gd}_{0.6} \mathrm{Co}_{0.2} \mathrm{Fe}_{0.2}\right)_{95} \mathrm{~B}_{x} \mathrm{Si}_{5-x}(x=0,2,5)$ amorphous alloy ribbons were fabricated, and their magnetic and magnetocaloric properties were investigated. The addition of covalent $\mathrm{B}$ or $\mathrm{Si}$ to $\mathrm{Gd}_{60} \mathrm{Co}_{20} \mathrm{Fe}_{20}$ causes a reduction in $T_{\mathrm{C}}$ and sharpens the magnetic transition process. Especially, $\left(\mathrm{Gd}_{0.6} \mathrm{Co}_{0.2} \mathrm{Fe}_{0.2}\right){ }_{95} \mathrm{~B}_{2} \mathrm{Si}_{3}$ co-doped with $\mathrm{B}$ and $\mathrm{Si}$ exhibits enhanced magnetocaloric performance with a larger $\left|\Delta S_{M}{ }^{p k}\right|$ of $2.25 \mathrm{~J} \mathrm{~kg}^{-1} \mathrm{~K}^{-1}$ at a higher working temperature of $222.5 \mathrm{~K}$ under an applied field change 
of 0-2 T. Due to the existence of a small amount of $\mathrm{Gd}_{4} \mathrm{Co}_{3}$ or $\mathrm{Gd}_{12} \mathrm{Co}_{7}$ phase precipitated from the amorphous matrix, the local structural inhomogeneity leads to a broadened $\left|\Delta S_{M}\right|-T$ curve and a high RCP of $396.0 \mathrm{~J} \mathrm{~kg}^{-1}$. The results indicate that the co-addition of $\mathrm{B}$ and $\mathrm{Si}$ to $\mathrm{Gd}_{60} \mathrm{Co}_{20} \mathrm{Fe}_{20}$ modifies the magnetic transition behavior and improves the magnetocaloric properties of the material, making the $\left(\mathrm{Gd}_{0.6} \mathrm{Co}_{0.2} \mathrm{Fe}_{0.2}\right)_{95} \mathrm{~B}_{2} \mathrm{Si}_{3}$ amorphous alloy a better candidate for magnetic refrigeration applications.

Author Contributions: Conceptualization, H.Z.; methodology, H.Z., Y.X. and Z.Z.; validation, H.Z., A.X. and W.L.; formal analysis, Y.X., Z.Z., H.P. and X.X.; investigation, Y.X., J.T., X.Z. and H.Z.; resources, A.X. and W.L.; data curation, H.Z. and H.L.; writing-original draft preparation, H.Z., Y.X. and Z.Z.; writing-review and editing, H.Z. and Y.X.; visualization, H.Z., Y.X. and Z.Z.; supervision, H.Z., A.X. and W.L.; project administration, H.Z.; funding acquisition, H.Z., H.P. and X.X. All authors have read and agreed to the published version of the manuscript.

Funding: The work was supported by the Natural Science Foundation of China (grant no. 51701003) and the Innovation and Entrepreneurship Training Program for College Students of the Anhui University of Technology (grant nos. S201910360193 and 202110360023).

Data Availability Statement: The data presented in this study are available on request from the corresponding author.

Acknowledgments: Authors would like to express gratitude to Xuguang Liu (from the Instruments Center for Physical Science, University of Science and Technology of China) and Wensen Wei (from the Hefei Institutes of Physical Science, Chinese Academy of Science) for help with performing PPMS and MPMS analyses, respectively.

Conflicts of Interest: The authors declare no conflict of interest.

\section{References}

1. Franco, V.; Blazquez, J.S.; Ipus, J.J.; Law, J.Y.; Moreno-Ramirez, L.M.; Conde, A. Magnetocaloric effect: From materials research to refrigeration devices. Prog. Mater. Sci. 2018, 93, 112-232. [CrossRef]

2. Kitanovski, A. Energy applications of magnetocaloric materials. Adv. Energy Mater. 2020, 10, 1903741. [CrossRef]

3. Gottschall, T.; Skokov, K.P.; Fries, M.; Taubel, A.; Radulov, I.; Scheibel, F.; Benke, D.; Riegg, S.; Gutfleisch, O. Making a cool choice: The materials library of magnetic refrigeration. Adv. Energy Mater. 2019, 9, 1901322. [CrossRef]

4. Pecharsky, V.K.; Gschneidner, K.A., Jr. Giant magnetocaloric effect in $\mathrm{Gd}_{5}\left(\mathrm{Si}_{2} \mathrm{Ge}_{2}\right)$. Phys. Rev. Lett. 1997, 78, 4494-4497. [CrossRef]

5. Hu, S.Y.; Miao, X.F.; Liu, J.; Ou, Z.Q.; Cong, M.Q.; Haschuluu, O.; Gong, Y.Y.; Qian, F.J.; You, Y.R.; Zhang, Y.J.; et al. Small hysteresis and giant magnetocaloric effect in $\mathrm{Nb}$-substituted $(\mathrm{Mn}, \mathrm{Fe})_{2}(\mathrm{P}, \mathrm{Si})$ alloys. Intermetallics 2019, 114, 106602. [CrossRef]

6. Moreno-Ramirez, L.M.; Diaz-Garcia, A.; Law, J.Y.; Giri, A.K.; Franco, V. Hysteresis, latent heat and cycling effects on the magnetocaloric response of $(\mathrm{NiMnSi})_{0.66}\left(\mathrm{Fe}_{2} \mathrm{Ge}\right)_{0.34}$ alloy. Intermetallics 2021, 131, 107083. [CrossRef]

7. Morrison, K.; Sandeman, K.G.; Cohen, L.F.; Sasso, C.P.; Basso, V.; Barcza, A.; Katter, M.; Moore, J.D.; Skokov, K.P.; Gutfleisch, $\mathrm{O}$. Evaluation of the reliability of the measurement of key magnetocaloric properties: A round robin study of $\mathrm{La}(\mathrm{Fe}, \mathrm{Si}, \mathrm{Mn}) \mathrm{H}_{\delta}$ conducted by the SSEEC consortium of European laboratories. Int. J. Refrig. 2012, 35, 1528-1536. [CrossRef]

8. Guo, J.; Xie, L.; Liu, C.; Li, Q.; Huo, J.; Chang, C.; Li, H.; Ma, X. Effect of Co/Ni substituting Fe on magnetocaloric properties of Fe-based bulk metallic glasses. Metals 2021, 11, 950. [CrossRef]

9. Huang, L.W.; Tang, B.Z.; Ding, D.; Wang, X.; Xia, L. Achieving high adiabatic temperature change at room temperature in a $\mathrm{Gd}_{48} \mathrm{Co}_{50} \mathrm{Fe}_{2}$ amorphous alloy. J. Alloys Compd. 2019, 811, 152003. [CrossRef]

10. Tang, B.Z.; Xie, H.X.; Li, D.M.; Xia, L.; Yu, P. Microstructure and its effect on magnetic and magnetocaloric properties of the $\mathrm{Co}_{50} \mathrm{Gd}_{50-x} \mathrm{Fe}_{x}$ glassy ribbons. J. Non-Cryst. Solids 2020, 533, 119935. [CrossRef]

11. Liu, G.L.; Zhao, D.Q.; Bai, H.Y.; Wang, W.H.; Pan, M.X. Room temperature table-like magnetocaloric effect in amorphous $\mathrm{Gd}_{50} \mathrm{Co}_{45} \mathrm{Fe}_{5}$ ribbon. J. Phys. D Appl. Phys. 2016, 49, 055004. [CrossRef]

12. Tang, B.Z.; Guo, D.Q.; Ding, D.; Xia, L.; Chan, K.C. Large adiabatic temperature rise above the water ice point of a minor Fe substituted $\mathrm{Gd}_{50} \mathrm{Co}_{50}$ amorphous alloy. J. Non-Cryst. Solids 2017, 464, 30-33. [CrossRef]

13. Zhang, H.Y.; Ouyang, J.T.; Ding, D.; Li, H.L.; Wang, J.G.; Li, W.H. Influence of Fe substitution on thermal stability and magnetocaloric effect of $\mathrm{Gd}_{60} \mathrm{Co}_{40-x} \mathrm{Fe}_{x}$ amorphous alloy. J. Alloys Compd. 2018, 769, 186-192. [CrossRef]

14. Duc, N.T.M.; Shen, H.X.; Clements, E.M.; Thiabgoh, O.; Sanchez Llamazares, J.L.; Sanchez-Valdes, C.F.; Huong, N.T.; Sun, J.F.; Srikanth, H.; Phan, M.H. Enhanced refrigerant capacity and Curie temperature of amorphous $\mathrm{Gd}_{60} \mathrm{Fe}_{20} \mathrm{Al}_{20}$ microwires. J. Alloys Compd. 2019, 807, 151694. [CrossRef]

15. Yuan, F.; Li, Q.; Shen, B.L. The effect of Fe/Al ratio on the thermal stability and magnetocaloric effect of $\mathrm{Gd}_{55} \mathrm{Fe}_{x} \mathrm{Al}_{45-x}(x=15-35)$ glassy ribbons. J. Appl. Phys. 2012, 111, 07A937. [CrossRef] 
16. Yano, K.; Kita, E. Effect of covalent element boron on exchange interaction and magnetic moment in $\mathrm{Fe}_{0.4} \mathrm{Gd}_{0.6}$ binary alloy. J. Magn. Magn. Mater. 2004, 272, 1370-1371. [CrossRef]

17. Krenke, T.; Duman, E.; Acet, M.; Wassermann, E.F.; Moya, X.; Manosa, L.; Planes, A. Inverse magnetocaloric effect in ferromagnetic Ni-Mn-Sn alloys. Nat. Mater. 2005, 4, 450-454. [CrossRef]

18. McMichael, R.D.; Ritter, J.J.; Shull, R.D. Enhanced magnetocaloric effect in $\mathrm{Gd}_{3} \mathrm{Ga}_{5-x} \mathrm{Fe}_{x} \mathrm{O}_{12}$. J. Appl. Phys. 1993, 73, 6946-6948. [CrossRef]

19. Han, P.; Zhang, Z.; Tan, J.; Zhang, X.; Xu, Y.; Zhang, H.; Li, W. Observation of a Broadened Magnetocaloric Effect in Partially Crystallized $\mathrm{Gd}_{60} \mathrm{Co}_{40}$ Amorphous Alloy. Metals 2021, 11, 1741. [CrossRef]

20. Son, H.; Yoo, G.; Mustaghfiroh, Q.; Kim, D.H.; Choi-Yim, H. Effect of Substituting Hf for Zr on Fe-Co-M-Nb-B (M = Zr, Hf) Amorphous Alloys with High Saturation Magnetization. Metals 2022, 12, 12. [CrossRef]

21. Suryanarayana, C.; Inoue, A. Bulk Metallic Glasses, 1st ed.; CRC Press; Taylor \& Francis Group: Boca Raton, FL, USA, 2011; pp. 188-214.

22. Yano, K.; Akiyama, Y.; Tokumitsu, K.; Kita, E.; Ino, H. Magnetic moment and Curie temperature for amorphous $\mathrm{Fe}_{100-X} \mathrm{Gd}_{X}$ alloys $(18 \leqq X \leqq 60)$. J. Magn. Magn. Mater. 2000, 214, 217-224. [CrossRef]

23. Yano, K. Molecular field analysis for melt-spun amorphous $\mathrm{Fe}_{100-x} \mathrm{Gd}_{x}$ alloys $(18 \leqq X \leqq 60)$. J. Magn. Magn. Mater. 2000, 208, 207-216. [CrossRef]

24. Schwarz, B.; Podmilsak, B.; Mattern, N.; Eckert, J. Magnetocaloric effect in Gd-based $\mathrm{Gd}_{60} \mathrm{Fe}_{x} \mathrm{Co}_{30-x} \mathrm{Al}_{10}$ metallic glasses. J. Magn Magn. Mater. 2010, 322, 2298-2303. [CrossRef]

25. Du, Y.S.; Zhang, C.H.; Lu, Y.M.; Li, L.; Li, J.Q.; Ma, L.; Rao, G.H. Table-like magnetocaloric effect and large refrigerant capacity in $\mathrm{Nd}_{6} \mathrm{Fe}_{13} \mathrm{Pd}_{1-x} \mathrm{Ag}_{x}$ compounds. Intermetallics 2021, 130, 107062. [CrossRef]

26. Yu, P.; Chen, L.S.; Xia, L. Phase separation and its effect on the magnetic entropy change profile in an amorphous $\mathrm{Gd}_{48} \mathrm{Co}_{50} \mathrm{Nb}_{2}$ alloy. J. Non-Cryst. Solids 2018, 493, 82-85. [CrossRef]

27. Wang, Y.F.; Qin, F.X.; Luo, Y.; Wang, H.; Peng, H.X. Tuning of magnetocaloric effect and optimization of scaling factor for $\mathrm{Gd}_{55} \mathrm{Ni}_{10} \mathrm{Co}_{35}$ amorphous microwires. J. Alloys Compd. 2018, 761, 1-7. [CrossRef]

28. Fang, Y.; Yu, Z.; Peng, G.; Feng, T. Near room-temperature magnetocaloric effect in amorphous Fe-Sc alloys: The effect of minor Co additions. J. Non-Cryst. Solids 2019, 505, 211-214. [CrossRef]

29. Alouhmy, M.; Moubah, R.; Alouhmy, G.; Abid, M.; Lassri, H. Effects of hydrogen implantation on the magnetocaloric properties of amorphous FeZr films. Vacuum 2021, 186, 110063. [CrossRef]

30. Shishkin, D.A.; Gazizov, A.I.; Volegov, A.S.; Gaviko, V.S.; Baranov, N.V. Magnetic properties and magnetocaloric effect of melt-spun $\mathrm{Gd}_{75}\left(\mathrm{Co}_{1-x} \mathrm{Fe}_{x}\right)_{25}$ alloys. J. Non-Cryst. Solids 2017, 478, 12-15. [CrossRef]

31. Zhang, Z.; Tang, Q.; Wang, F.; Zhang, H.; Zhou, Y.; Xia, A.; Li, H.; Chen, S.; Li, W. Tailorable magnetocaloric effect by Fe substitution in Gd-(Co, Fe) amorphous alloy. Intermetallics 2019, 111, 106500. [CrossRef]

32. Wu, C.; Ding, D.; Xia, L.; Chan, K.C. Achieving tailorable magneto-caloric effect in the Gd-Co binary amorphous alloys. AIP Adv. 2016, 6, 035302. [CrossRef]

33. Qin, F.X.; Bingham, N.S.; Wang, H.; Peng, H.X.; Sun, J.F.; Franco, V.; Yu, S.C.; Srikanth, H.; Phan, M.H. Mechanical and magnetocaloric properties of Gd-based amorphous microwires fabricated by melt-extraction. Acta Mater. 2013, 61, 1284-1293. [CrossRef]

34. Oesterreicher, H.; Parker, F.T. Magnetic cooling near Curie temperatures above 300 K. J. Appl. Phys. 1984, 55, 4334-4338. [CrossRef]

35. Franco, V.; Conde, A.; Kuz'min, M.D.; Romero-Enrique, J.M. The magnetocaloric effect in materials with a second order phase transition: Are $T_{C}$ and $T_{\text {peak }}$ necessarily coincident? J. Appl. Phys. 2009, 105, 07A917. [CrossRef]

36. Franco, V.; Blázquez, J.S.; Conde, A. Field dependence of the magnetocaloric effect in materials with a second order phase transition: A master curve for the magnetic entropy change. Appl. Phys. Lett. 2006, 89, 222512. [CrossRef]

37. Duc, N.T.M.; Shen, H.X.; Clements, E.; Thiabgoh, O.; Llamazares, J.L.S.; Sanchez-Valdes, C.F.; Huong, N.T.; Sun, J.F.; Srikanth, H.; Phan, M.H. Critical magnetic and magnetocaloric behavior of amorphous melt-extracted $\mathrm{Gd}_{50}\left(\mathrm{Co}_{69.25} \mathrm{Fe}_{4.25} \mathrm{Si}_{13} \mathrm{~B}_{13.5}\right)_{50}$ microwires. Intermetallics 2019, 110, 106479. [CrossRef]

38. Zhang, H.; Li, R.; Xu, T.; Liu, F.; Zhang, T. Near room-temperature magnetocaloric effect in FeMnPBC metallic glasses with tunable Curie temperature. J. Magn. Magn. Mater. 2013, 347, 131-135. [CrossRef]

39. Zheng, Z.G.; Zhong, X.C.; Liu, Z.W.; Zeng, D.C.; Franco, V.; Zhang, J.L. Magnetocaloric effect and critical behavior of amorphous $\left(\mathrm{Gd}_{4} \mathrm{Co}_{3}\right)_{1-x} \mathrm{Si}_{x}$ alloys. J. Magn. Magn. Mater. 2013, 343, 184-188. [CrossRef] 